\title{
The need for new environmental practices for the preservation of Natural Resources
}

\author{
SILVA, Anderson Nunes da ${ }^{1}$. OLIVEIRA, Vanessa Ávalo de ${ }^{2}$. MAIA, Jaqueline Pinheiro Siqueira ${ }^{3}$.
}

UEMS (Universidade Estadual de Mato Grosso do Sul)

E-mail: andjur@outlook.com ${ }^{1}$; vanessa.avalo@outlook.com²; jaquelinepsmaiaadv@gmail.com³

\begin{abstract}
This study aims to collect statistical data related to the numbers of forest fires that occurred in the state of Mato Grosso do Sul in recent years, practiced by the population of Mato Grosso do Sul in observance of the lack of adoption of environmental education practices to reduce these numbers and consequent preservation of the environment. It can be seen in this context that in the four months of this year, there was an increase in fires to $239 \%$ related to the same months of the previous year, $57 \%$ of which occurred in the municipality of Corumbá, as a result of human failure. The concern with environmental problems and the need to promote new practices is mainly foreseen in the Federal Constitution of 1988, in item VI of article 225, in which it highlights the need to promote it at all levels of education, as well as to develop public awareness for the preservation of the environment. Therefore, being aware of the damage done to the environment, reflecting the lack of awareness and misuse of the environment in which one lives, is more than necessary and relevant for the current moment. The prevention of forest fires by means of educational projects and programs, using new practices, with the most diverse forms of communication with human beings, in addition to making them aware of their dependence on the natural resources that we obtain from their own land, bringing the application of new ideas of prevention into practice, as an example of rigorous inspection of the relevant legislation that already exists in the society of the region that lives with the scenario of the consequences of the Forest Fire.In this sense, we expect improvements in the actions of fire prevention and combat institutions, as well as of the population itself, covering all age groups, as well as a new political / educational vision on the issue that integrates the social, educational and ecological needs of the entire environment.
\end{abstract}

Keywords: environmental education, forest fires, new practices. 